\title{
DESARROLLO DE CAPSULAS Y GERMINACION IN VITRO DE PHRAGMIPEDIUM HUMBOLDTII, P. LONGIFOLIUM Y P. PEARCEI
}

\author{
Melania MuÑoz ${ }^{1,2,3} \&$ Víctor M. JimÉNEZ ${ }^{1,2}$ \\ ${ }^{1}$ Jardín Botánico Lankester, Universidad de Costa Rica, Cartago, Costa Rica. \\ ${ }^{2}$ CIGRAS, Universidad de Costa Rica, 2060 San Pedro, Costa Rica. \\ ${ }^{3}$ Author for correspondence: melaniamunozg@yahoo.com
}

\begin{abstract}
Slipper orchids belonging to the genus Phragmipedium (subfam. Cypripedioideae) are seriously threatened and therefore listed in Appendix I of CITES. Less research has been conducted in this genus than in others belonging to the same subfamily. In this work, we evaluated development of capsules (seed pods) from Phragmipedium humboldtii, $P$. longifolium and $P$. peaarcei from the time of pollination until opening. Moreover, seed viability was tested with the tetrazolium method in each of the capsules that were subsequently used to evaluate the effect of light and two culture media (Knudson C vs. Murashige and Skoog half concentrated) on in vitro asymbiotic germination and seedling growth. $100 \%$ of the pollinated flowers developed capsules, which differentiated in terms of length and diameter among species. While the length of the capsules remained constant during development, their diameter increased during the first 6-8 weeks and then stopped. Time required for maturity and opening of the capsules also varied among species (31 weeks in $P$. humboldtii, 16 weeks in $P$. longifolium and 9.5 weeks in $P$. percei). Seed viability differed among species as well, averaging $34.3 \%$ in $P$. humboldtii, $44.7 \%$ in $P$. longifolium and $82.3 \%$ in $P$. pearcei. Furthermore, seed viability of each capsule was used to adjust the germination rate measured in each case. While very few $P$. humboldtii viable seeds germinated under the conditions tested (2.9\%), better results were observed in the other two species (close to $40 \%$ germination). No significant effect of light/darkness regime or of culture medium was observed on germination. However, better growth of the germinated embryos was observed with the Knudson $\mathrm{C}$ medium and darkness conditions. Further subculture of the growing plantlets under light conditions induced development of roots and allowed successful acclimatization of seedlings in the greenhouse.
\end{abstract}

Palabras Clave: Phragmipedium, orquídeas terrestres, polinización, desarrollo de cápsulas, cloruro de tetrazolio, germinación in vitro.

Las orquídeas del género Phragmipedium Rolfe (subfamilia Cypripedioideae), comúnmente llamadas zapatillas o "slipper orchids", se encuentran naturalmente distribuidas en Meso y Suramérica (Cox et al. 1998, Dressler 2003). Estas plantas están en peligro de extinción por alteración o destrucción de su hábitat y por la extracción masiva de plantas de su ambiente natural (Arditti 1992, Salazar 1996).

El hecho de que el género Phragmipedium haya sido relativamente poco estudiado probablemente se debe al hecho de que si bien algunas especies producen flores vistosas, su cultivo no es fácil, lo cual ha limitado su atractivo para coleccionistas y viveristas. Este estudio pretende describir el desarrollo y determinar el tiempo de maduración de cápsulas de $P$. humboldtii, P. longifolium y P. pearcei, así como evaluar la viabilidad de las semillas en las mismas, y establecer un método para la germinación in vitro de semillas maduras de estas tres especies y el desarrollo posterior de plántulas.

\section{Materiales y métodos}

Se polinizaron manualmente flores de plantas de Phragmipedium humboldtii, de $P$. longifolium y de $P$. pearcei, en cultivo en el Jardín Botánico Lankester de la Universidad de Costa Rica. Cada semana, a partir de la fecha de polinización, se midió el largo y el diámetro de cada cápsula. Además, se determinó el tiempo transcurrido para la apertura de cada cápsula. Parte de las semillas de las cápsulas abiertas de las plantas mencionadas anteriormente se utilizaron para medir el porcentaje de viabilidad mediante el método 
de tinción con cloruro de tetrazolio (Singh 1981). Se desinfectaron las semillas restantes en cada cápsula mediante agitación durante $10 \mathrm{~min}$ en hipoclorito de sodio $(0.6 \%)$ adicionado con Tween 80 ( 1 gota/100 $\mathrm{ml}$ ), seguida de tres lavados con agua destilada estéril. Las semillas se colocaron en placas de Petri de 90 $\mathrm{mm}$ de diámetro con $20 \mathrm{ml}$ de medio de cultivo semisólido. Para la germinación in vitro, se evaluaron los medios de cultivo Knudson C (Knudson 1946) y Murashige y Skoog (1962) utilizando, en este último, las concentraciones de macro y micronutrientes al $50 \%$ (MS 50\%). Ambos medios fueron complementados con $1 \mathrm{mg} / \mathrm{l}$ de tiamina, ácido nicotínico y piridoxina y $20 \mathrm{~g} / 1$ de sacarosa. El pH se ajustó a 5.7 y los medios fueron gelificados con $0.8 \%$ de agar. La temperatura de cultivo fue $25 \pm 1{ }^{\circ} \mathrm{C}$. Se evaluó la germinación en oscuridad y en un fotoperíodo de $12 \mathrm{~h}$ $\left(10.9 \mu \mathrm{mol} \mathrm{m}^{-2} \mathrm{~s}^{-1}\right.$, Sylvania Supersaver Cool White, $32 \mathrm{~W}, \mathrm{~F} 48 \mathrm{~T} 12 / \mathrm{CW} / \mathrm{SS})$.

Para determinar el porcentaje de germinación, en cada placa se marcaron tres áreas de aproximadamente $1 \mathrm{~cm}^{2}$. Se cuantificó el número inicial de semillas en cada área el día en que se cultivaron. En cada evaluación se contó el número de semillas germinadas. Se utilizaron tres placas de Petri para cada una de las combinaciones de tratamientos de medios de cultivo y régimen lumínico por especie. El porcentaje de germinación se corrigió utilizando el porcentaje de viabilidad de cada cápsula.

Las plantas obtenidas fueron aclimatadas en recipientes plásticos $(3 \times 3 \times 4 \mathrm{~cm})$ con turba picada. Se utilizó riego por nebulización (4 s cada $15 \mathrm{~min}$ durante el día).

Se realizó un análisis de varianza (ANDEVA) y se utilizó la prueba de Tukey para comparación de medias (Statistica, StatSoft, Tulsa, OK, EUA) para determinar diferencias entre especies y tratamientos.

\section{Resultados}

Todas las flores polinizadas formaron cápsula. Las cápsulas más grandes fueron las de $P$. humboldtii, cuyo tamaño promedio, una semana antes de la apertura, fue $182,7 \pm 3,2 \mathrm{~mm} \times 7.0 \pm 0.2 \mathrm{~mm}$, seguidas por las de $P$. longifolium $(60.02 \pm 2.0 \mathrm{~mm} \times 5.6 \pm 0.1 \mathrm{~mm})$, y las cápsulas más pequeñas fueron la de $P$. pearcei $(42.5 \pm 1.4 \mathrm{~mm} \times 4.2 \pm 0.1 \mathrm{~mm}) \quad$ Las cápsulas de $P$. humboldtii fueron las que tardaron más tiempo en abrir (31 semanas), mientras que las de $P$. longifolium y las de $P$. pearcei duraron un promedio de 16 y 9.5 semanas, respectivamente.

La viabilidad promedio de las semillas fue de $34.3 \%$ en las cápsulas de $P$. humboldtii, de $44.7 \%$ en $P$. longifolium y de $82.3 \%$ en $P$. pearcei. El porcentaje de viabilidad de cada cápsula se utilizó para corregir el porcentaje de germinación en cada caso. Este porcentaje de germinación corregido fue menor en $P$. humboldtii $(2.9 \%)$ que en $P$. longifolium $(41.3 \%)$ y en $P$. pearcei $(38.7 \%)$, sin que hubiera diferencias significativas entre estos dos últimos.

Ni el medio de cultivo ni el régimen lumínico utilizados tuvieron efecto sobre la germinación de las especies estudiadas $(\mathrm{p}>0.05)$. Sí se observó un mejor crecimiento de los protocormos de $P$. pearcei y de $P$. longifolium en el medio Knudson $\mathrm{C}$ que en el MS $50 \%$. Además, dentro de los cultivados en Knudson $\mathrm{C}$, se observó un mejor crecimiento de los protocormos germinados en la oscuridad. Estos se pasaron a fotoperíodo de 12 horas después de 6 semanas de cultivo, y una semana después empezaron a cambiar su coloración de blanco a verde.

Los protocormos de $P$. pearcei y P. longifolium empezaron a desarrollar la primera hoja a las cuatro semanas después de la siembra de las semillas, mientras que en $P$. humboldtii esta se empezó a desarrollar en la semana ocho de cultivo. Después de tres meses de cultivo, las plántulas de $P$. pearcei y $P$. longifolium tenían dos o más hojas y empezaron a desarrollar raíces a los tres meses y medio. Se logró aclimatar con éxito todas las plantas transferidas al invernadero, siguiendo la metodología descrita anteriormente.

\section{Conclusiones}

En este estudio se describieron las curvas de crecimiento y se determinó el tiempo que necesitan las cápsulas de $P$. humboldtii, $P$. longifolium y $P$. pearcei para llegar a madurez y abrirse. Esto último es muy útil para determinar el momento adecuado para la recolecta de cápsulas inmaduras, las cuales son más fáciles de desinfectar en estas condiciones. Además, en este trabajo se describe un método efectivo para la germinación y el desarrollo de plántulas de las tres especies de Phragmipedium estudiadas. 
Mediante este procedimiento se puede multiplicar gran cantidad de plantas de este género, manteniendo una variabilidad genética mayor a la obtenida mediante la propagación clonal. Esto es muy ventajoso para la producción de plantas con fines de conservación de la especie.

Agradecimientos. Este trabajo fue financiado parcialmente por la Vicerrectoría de Investigación de la Universidad de Costa Rica, en el marco del proyecto: "Evaluación de la variabilidad genética de poblaciones silvestres y cultivo in vitro de Phragmipedium (Orchidaceae) en Costa Rica" (VI-814-A6-107).

\section{LITERATURA CITADA}

Arditti, J. 1992. Fundaments of Orchid Biology. John Wiley \& Sons, Inc., EUA. 691p.

Cox, A.V., A.M. Pridgeon \& M.W. Chase. 1998. The utility of DNA sequence data in orchid systematics: an example from the slipper orchids (Cypripedioideae), pp. 265-273. In: C. E. B. Pereira (ed.). Proceedings of $15^{\text {th }}$ World Orchid Conference. Naturalia, Francia.

Dressler, R.L. 2003. Orchidaceae, pp. 1-595. In: Hammel, B.E., Grayum, M.H., Herrera, C. \& Zamora, N. (eds.). Manual de Plantas de Costa Rica, vol III: Monocotiledóneas (Orchidaceae-Zingiberaceae). Missouri Botanical Garden. San Luis, Misuri.

Knudson, L. 1946. A new nutrient solution for the germination of orchid seed. Amer. Orchid Soc. Bull. 15:214-217.

Murashige, T. \& F. Skoog. 1962. A revised medium for rapid growth and bioassays with tobacco tissue culture. Physiol. Plant. 15: 473-497.

Salazar, G.A. 1996. Conservation Threats, pp. 6-10. In: Hágsater, E \& V. Dumont (eds.). Orchids- Status Survey and Conservation Action Plan. IUCN. Gland Switzerland and Cambridge, UK.

Singh, F. 1981. Differential staining of orchids seeds for viability testing. Amer. Orchid Soc. Bull. 50: 416418 .

Melania Muñoz obtuvo el título de Bachiller en Biología de la Universidad de Costa Rica en el año 2003. Actualmente realiza sus estudios de Posgrado en Biotecnología en la misma universidad. Su proyecto de tesis está enfocado en la genética de poblaciones y reproducción in vitro de orquídeas. Es asistente de investigación en el Jardín Botánico Lankester. Desde el 2004 trabaja en la Reserva Biológica Bosque de Paz, donde realiza el inventario del Jardín de Orquídeas y es la encargada del montaje y mantenimiento del herbario.

Víctor M. Jiménez obtuvo su doctorado en ciencias agrícolas en la Universidad de Hohenheim, Stuttgart, Alemania, estudiando la regulación hormonal de la embriogénesis somática en varias especies vegetales. Es profesor catedrático en la Escuela de Agronomía y en el Programa de Posgrado en Ciencias Agrícolas y Recursos Naturales y se desempeña como investigador en el Centro para Investigaciones en Granos y Semillas (CIGRAS) y en el Jardín Botánico Lankester, todos de la Universidad de Costa Rica. Actualmente realiza una pasantía de investigación en StuttgartHohenheim, apoyado por la Fundación Alexander von Humboldt. 